\title{
The Prediction Method of Typical Economy Index in Network Accounting based on Fractal Theory
}

\author{
Junling Shen*
}

Nanyang Normal University, Henan, Nanyang, 473061, China

\begin{abstract}
Along with the arrival of network financial information times, network accounting emerges. Accounting means have undergone through handwork accounting and computer to replace the changes of handwork accounting, database and network. Maximum share of accounting information resource can be realized by network accounting, which accelerates the accounting affairs handing, making the centralized management easier and providing with endurance to the full development for the electronic business.
\end{abstract}

Keywords: Fractal theory, network accounting, prediction method, typical economy index.

\section{INTRODUCTION}

The purpose of 'integrated financial information' provisioned by an enterprise is to provide report users with financial and non-financial information related to the substantial and financial condition of the enterprise. In accounting, substantial and financial conditions are prioritized according to legal aspects the concept of integrated financial information. Therefore, if financial report users merely read financial reports from a single enterprise, they would fail to gain an accurate insight into the overall economic activities occurring in the business group [1]. As a result, the parent company needs to compile integrated financial information to integrate the business conditions of all its affiliate companies and present as a single financial entity. Therefore, report users are able to clearly understand the overall financial conditions of the financial entity, its business performance, and changes in the financial conditions.

Integrated financial information involves multiple enterprise entities. The transactions that take place in these reportcompiling entities are often complex. When compiling integrated financial information, the confirmation of the bodies of integrated financial information and the internal transaction write-offs in affiliate companies are two important issues [2]. In the global layout of enterprises, the parent and subsidiary companies are distributed worldwide, and different currencies are used to compute unit prices. Reports based on accounting standards of different nations have made it much more difficult for enterprises to compile financial reports.

In the past ten years, Local fractional calculus $[3,4]$ has been widely applied to many fields such as mathematics, image processing and signal processing etc. Some authors have given many definitions of local fractional derivatives and local fractional integrals (also called fractal calculus) [5].
Hereby we rewrite the following local fractional derivative which is given by [6].

In this paper, in order to make the prediction method of typical economy index in network accounting more reasonable, local fractional Hilbert transform in fractal space is established. The characteristics of this local fractional transform are discussed in the following. Considering the basic properties of the local fractional Hilbert transforms and also a kind of transform for local fractional is derived and analyzed [7].

\section{THE INADAPTABILITY OF TRADITIONAL AC- COUNTING BUSINESS UNDER THE INFORMATION TIMES}

Interior enterprise has much business process. Each process has the business processing activities such as input, output and input turning into the output. Accounting business process is the same. Generally, it is divided into accounting data collection, accounting data processing, accounting data output and accounting data storage, and so on. Under the traditional environment, accounting data is stored in the paper medium. Accounting data collection and processing are completed by hand, so it is easy to make a mistake with heavy data processing workload. Under the information environment, there are some factors as follows:

The Efficiency of the Traditional Accounting Business: Under the traditional environment, financial accounting personnel collect all kinds of original documents, and to fill vouchers of proof after the approval, according to the original vouchers and accounting system. In this way, it will store the data which reflects economic business accounting in accounting voucher. Proof of charge generally fall into receipts, the payment and transfer voucher. Cashier personnel register cash journal and bank deposit journal according to the receipts and payment voucher; According to the size of the enterprise business, there should be several accounting personnel to register subsidiary ledger, cost subsidiary ledger and inventory subsidiary ledger as well as all kinds of de- 
tailed books; General accounting leader is responsible for registering general ledger and repairing financial statements. Because the work of the registration books is completed by several working personnel, it will inevitably appear errors. So we must check the general ledger and subsidiary ledger, general ledger and journal. In the above accounting business processing process, the work of data processing such as the transmission, sorting, consolidation, calculation, check, inquiry of documents and books are done respectively by hand. All kinds of data are stored in the form of paper. At the final accounting time in the special period, accounting personnel need to get the books and accounting information data, and carries on them to complete the making of various statements [8]. During this period, the work of making statements can only be finished by calculation, analysis, and combination and so on. If it is found that the data is uneven or mistaken, it needs to reorganize. So, the disadvantages of the traditional accounting business process are data processing workload is bigger. Error rate is high and low efficiency.

The Personal Needs of Users for the Traditional Accounting Business: Under the traditional environment, accounting business process, the report of assets status and using efficiency to the owner of the enterprise is based on original cost, and the target require is relatively single. But under the information environment, the usefulness of decision is taken as a main target of accounting, especially in the era of information economy, potential investors and capital market widely exist, accounting forecast and analysis often use the market value of the assets, not the original value of the assets. At the same time, the investment way of the owner has changed. Under the environment of economic globalization, there are many factors influence the capital market, and the market value of assets is always changing. Therefore, they put forward higher request to accounting information timeliness and relativity. While the traditional accounting business process does not fully consider the important role of the accounting information to investors' decision making, it considers more of the reliability of accounting information, but less for investors' timeliness and relativity demand of accounting information.

Under the financial information environment, the accounting is dynamic. The target of enterprise accounting process reorganization is to realize the integration of financial and business, so makes the enterprise do real-time accounting business processing and to achieve a better synchronization and coordination of information collection and information processing, the enterprise can timely generate and transfer dynamic financial statements and financial reports which reflect the enterprise's operation state capital condition to the corresponding outside investors, creditors and governmental and other information needs, in order to provide useful information to the enterprise to make it response promptly to the changing economic environment.

Full Utility of Information Technology: In the financial information times, the share of the accounting data resource is realized by making full use of the information technology and the network technology. Under information environment, the accounting information system has changed into an open system, which fundamentally promotes the enterprise internal, internal and external's exchange of information and resource sharing. For the internal enterprise, information can be transferred and exchanged between the accounting information system and national subsystems by enterprise LAN. For example, the wage cost allocation vouchers produced by salary system, fixed assets increase, reduce and depreciation by fixed assets system, collection, send and preservation of vouchers generated by materials system will be turned to accounting treatment system, after the processing of accounting treatment system, then passed to the corresponding subsystem according to need, for example, after compiling the certificate involving cost, expenses, then, transferring to cost subsystem. For another example, as long as input the accounting treatment system, relevant personnel information, department files information, customer information and supplier information and other systems can be used directly, there is no need to input relevant data again, which realizes a data input can be used many times, in order to realize fully sharing of data of enterprise internal system. At the same time, the enterprise can also minimize time delay and data redundancy through Internet to reach the information exchange between the company and external system (customers, suppliers, banks, and tax, etc.)

Minimization for the Impact of the Asymmetric Information: Because of the different angle and purpose of information users, whether good or bad information to the enterprise should be given disclosure, so that users of the information can have a comprehensive understanding of the system on the financial situation of enterprise. But under the traditional environment, due to the limitations of manual processing and the disclosure means, it can neither reflect the nonquantitative and non-monetary information in accounting statement, nor reflect the accounting procedure and method information of the digital processing statements. However, under the information environment, the database of accounting information system includes the all the financial and non-financial information of enterprise, and through the online report means, effectively expands the information capacity and the disclosure range of accounting statements notes. So, under the information environment, the reflecting method should be more diversification and the amount and range of information should be enlarged, therefore, it will reduce asymmetry information problem under the traditional environment, which reduces the impact of wrong information to users to some extent.

Full Use of the Fair Value to Improve the Correlation: The correlation of accounting data aims at improving the usefulness of accounting data. It can better help enterprise to carry on the forecast and decision-making, and promote the accelerated development of accounting business. Under the information environment, the integration of financial business and the coordination of processing greatly reduce the cost of accounting treatment, especially with the development of capital market and a large number of existing potential investors, the fair value has all the measurement attributes of the relativity, and because of the development of information technology, it's easier to obtain the fair value. We can get the fair value of the assets on time through the network and other information technology. The existing of listed company and a large number of potential investors is pressing for more relevant accounting information. Therefore, under the information economy environment, we must 
modify the traditional accounting business process, not only retain strong reliability characteristics of the original cost, but also increase more strong related accounting information such as fair value, in order to meet the need of accounting business under information economy environment [9].

Efficiency Improvement by Using the XBRL Language Technology: Providing with online real-time accounting report synchronous to the enterprise business is also one of the main purposes of the accounting business process reorganization under the information environment. And XBRL provides vitality and vigor for accounting report output of accounting of business process reorganization. XBRL is the technology base of the realization of the on-line financial report. XBRL increases the transparency of the disclosure of financial report, and at the same time, it greatly enhances the efficiency and ability of processing financial report of information, which provides important technical support for the united format of the accounting output report. As long as the company adopt the same accounting information report of XBRL language disclosure, the company's information users can extract the messages they need conveniently, and analyze data information quickly; by using XBRL technology, the company's information users can not only analyze longitudinal cross the year conveniently, but also can make a horizontal comparison across many reports, many companies, many industry, many nations. At the same time we should also see that XBRL is only a kind of information technology, it can't take the place of any accounting standards and rules, and it can only provide advanced information technology support for information disclosure of the accounting business process [9]. So, when using XBRL technology in the process of accounting business process reorganization, we should integrate all accounting output technology report to realize reasonable cooperation of information technology and enterprise management idea, only by this can we fully use XBRL and improve the time efficiency of the accounting information.

\section{THE BASIC PATTERN OF PREDICTION METHOD OF TYPICAL ECONOMY INDEX IN NETWORK AC- COUNTING}

Like other enterprise business process, the reorganization of accounting business process under the information environment, do not negate the traditional business process, but to reform and add based on the traditional accounting process in order to make the transformed business process can better meet the need of information economy. Under the information environment, the storage way of documents has changed. Data processing method and the generation way of accounting report have changed too. An input data can be used for many times, so it seems that the control from collection to validation of accounting information is very important. Under the information environment, accounting business process is shown by Fig. (1).

The algorithm based on fractal theory can be expressed as following:

$f^{(\alpha)}(x 0)=\left.\frac{d f(x)}{d x^{\alpha}}\right|_{x=x_{0}}=\lim _{\delta x \rightarrow 0} \frac{\Delta^{\alpha}\left(f(x)-f\left(x_{0}\right)\right)}{\left(x-x_{0}\right)^{\alpha}}$

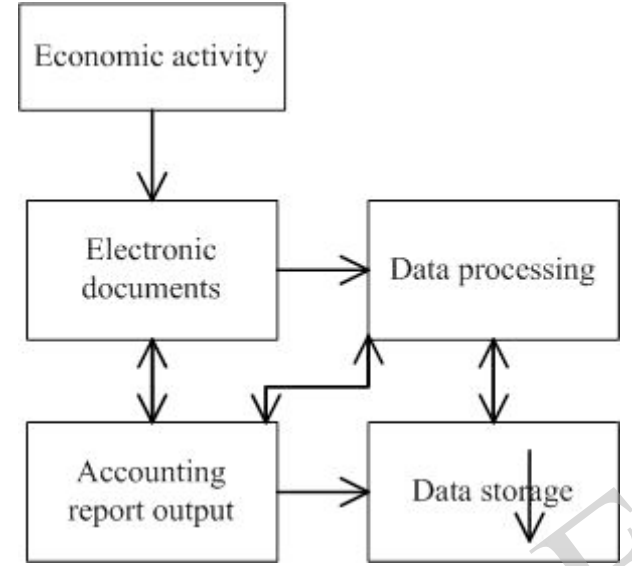

Fig. (1). Accounting business process under information environment.

for $0<a \leq 1$ where

$\Delta^{\alpha}\left(f(x)-f\left(x_{0}\right)\right) \cong \Gamma(1+\alpha) \lim _{x \rightarrow \infty} \Delta\left(f(x)-f\left(x_{0}\right)\right)$

And local fractional integral of $f(x)$ defined by Eq.3.

$$
\begin{aligned}
& { }_{a} I_{b}^{(\alpha)} f(t)=\frac{1}{\Gamma(1+\alpha)} \int_{a}^{b} f(t)(d t)^{\alpha} \\
& =\frac{1}{\Gamma(1+\alpha)} \lim _{\Delta t \rightarrow 0} \sum_{j=0}^{j=N-1} f\left(t_{\mathrm{j}}\right)\left(\Delta t_{\mathrm{j}}\right)^{\alpha} \\
& \text { With } \quad \Delta t_{j}=t_{j+1}-t_{j} \text { and } \Delta t=\max \left\{\Delta t_{1}, \Delta t_{2}, \cdots, \Delta t_{j}, \cdots\right\},
\end{aligned}
$$

where for $j=1,2, \cdots, N-1,\left[t_{j}, t_{j+1}\right]$ is a partition of the interval $[a, b]$ and $t_{0}=a, t_{N}=b$.

If $f(x)$ is defined on the real line $-\infty<x<\infty$, its local fractional Hilbert transform, denoted by $f_{x}^{H, \alpha}(x)$ is defined by

$$
H_{\alpha}\{f(t)\}=\hat{f}_{H}^{\alpha}(x)=\frac{1}{\Gamma(1+\alpha)} \int_{R} \frac{f(t)}{\Gamma(t-x)^{\alpha}}(d t)^{\alpha}
$$

where $x$ is real and the integral is treated as a Canchy principal value, that is,

$$
\begin{aligned}
& \frac{1}{\Gamma(1+\alpha)} \int_{R} \frac{f(t)}{\Gamma t-x)^{\alpha}}(d t)^{\alpha} \\
& =\lim _{\varepsilon \rightarrow 0}\left[\frac{1}{\Gamma(1+\alpha)} \int_{-\infty}^{x-\varepsilon} \frac{f(t)}{(t-x)^{\alpha}}(d t)^{\alpha}+\right. \\
& \left.\frac{1}{\Gamma(1+\alpha)} \int_{x+\varepsilon}^{\infty} \frac{f(t)}{(t-x)^{\alpha}}(d t)^{\alpha}\right]
\end{aligned}
$$

To obtain the inverse local fractional Hilbert transform, write again Eq. (4) as

$$
\begin{aligned}
& \hat{f}_{H}^{\alpha}(x)=\frac{1}{\Gamma(1+\alpha)} \int_{-\infty}^{\infty} \frac{f(t)}{(t-x)^{\alpha}}(d t)^{\alpha} \\
& =\frac{1}{\Gamma(1+\alpha)} \int_{-\infty}^{\infty} f(t) g(x-t)(d t)^{\alpha}=f(x) * g(x),
\end{aligned}
$$




\section{THE EXPERIMENT RESULTS}

In order to illustrate the actual effect after using network accounting based on fractal theory in prediction of typical economy index, we choose ten sets of typical economy index which is shown in Table $\mathbf{1}$.

Table 1. Ten sets of typical economy index.

\begin{tabular}{|c|c|c|}
\hline No. & Index & Weight \\
\hline \hline $\mathbf{1}$ & CPI & 25 \\
\hline $\mathbf{2}$ & NRV & 10 \\
\hline $\mathbf{3}$ & NOV & 10 \\
\hline $\mathbf{4}$ & E0 & 5 \\
\hline $\mathbf{5}$ & E1 & 5 \\
\hline $\mathbf{6}$ & E2 & 5 \\
\hline $\mathbf{7}$ & PPI & 15 \\
\hline $\mathbf{8}$ & KPI & 10 \\
\hline $\mathbf{9}$ & WSV & 8 \\
\hline $\mathbf{1 0}$ & KPR & 7 \\
\hline
\end{tabular}

The comparison before and after using network accounting based on fractal theory in prediction of typical economy index can be seen from Fig. (2). The result shows that in the same experimental time, after using the network accounting based on fractal theory it can achieve better performance in calculating time than before using it.

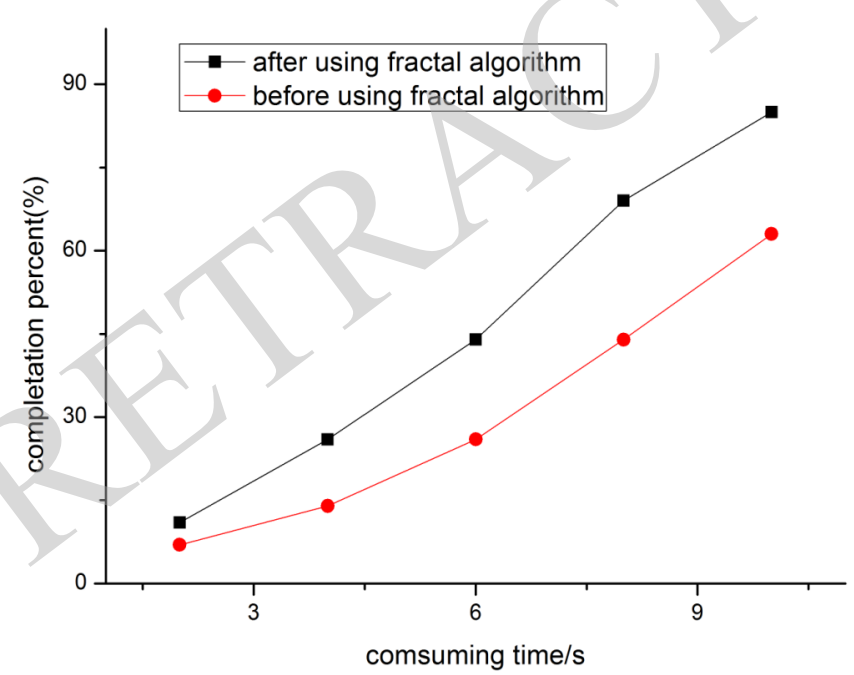

Fig. (2). The comparison before and after using fractal algorithm in calculating time.

The accuracy comparison before and after using network accounting based on fractal theory in prediction of typical economy index can be seen from Fig. (3). The result shows that in the same experimental time, after using the network accounting based on fractal theory it can achieve better performance in accuracy than before using it.

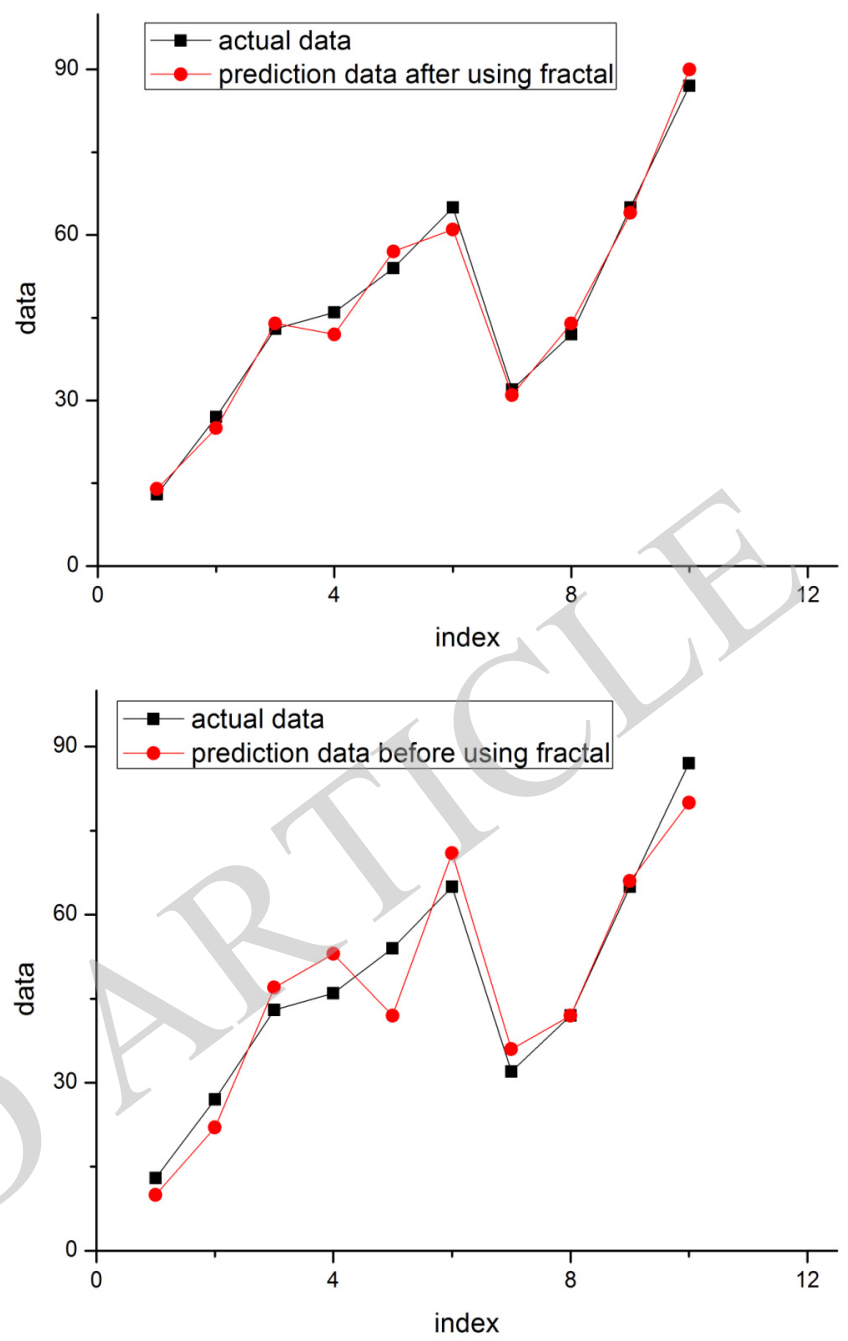

Fig. (3). The comparison before and after using fractal algorithm in accuracy.

\section{CONCLUSION}

Along with the arrival of high-tech information times, global network tendency quick infiltrate in every field, the appearance of network accounting seems to be a mushroom blowing in accounting development history. Under the financial information times, the enterprise relies on information technology more and more. To achieve the purpose of accounting and better play to the accounting role, we must reorganize the traditional accounting process, establish accounting business process which adapting to information economy environment and gradually improve the internal control system under the new process.

\section{CONFLICT OF INTEREST}

The authors confirm that this article content has no conflict of interest.

\section{ACKNOWLEDGEMENTS}

Declared none. 


\section{REFERENCES}

[1] J. Zhou, "The Reorganization of Accounting Business Process Based on The Reorganization of Business Process," Foreign Economic and Trade Finance and Accounting, no. 9, pp. 17-18, 2005.

[2] L. Zhang, "The Reconstruction of Accounting Process Based on Information Technology," no.24, pp. 36-37, 2006.

[3] X. Yi, "On the Reconstruction of Accounting Process under the ERP Environment," North Economic and Trade, no.1, pp. 78-79, 2004.

[4] Y. Li, "Age Accounting Process Reconstruction Discussion," Enterprise Economic, no.8, pp. 157-158, 2005.

[5] T. Zhang, "Network Financial Report On the theoretical framework and technology of XBRL," Fudan University Press, Shanghai, 2006.
[6] J. A. T. Machado, F. S. Manuel, S. B. Ramiro, S. J. Isabel, M. R. Cecília, G. M. Maria, and F. G. Alexandra, "Some Applications of Fractional Calculus in Engineering," Mathematical Problems in Engineering, Hindawi, vol. 2010, Article ID 639801, 2009. doi:10.1155/2010/639801.

[7] S.G. Samko, A.A. Kilbas, and O.I. Marichev, "Fractional Integrals and Derivatives: Theory and Applications," Gordon and Breach, pp. 164-170, 1993.

[8] K.M. Kolwankar, and A.D. Gangal, "Local Fractional FokkerPlanck Equation,” Phys. Rev. Lett. , no. 80, pp. 214-217, 1998.

[9] A. Babakhani, and V. Daftardar-Gejji, "On Calculus of Local Fractional Derivatives," J. Math. Anal. Appl., no. 270, pp. 66-79, 2002.

Received: September 16, 2014

Revised: December 23, 2014

Accepted: December 31, 2014

(C) Junling Shen; Licensee Bentham Open.

This is an open access article licensed under the terms of the Creative Commons Attribution Non-Commercial License (http://creativecommons.org/licenses/by-nc/3.0/) which permits unrestricted, non-commercial use, distribution and reproduction in any medium, provided the work is properly cited. 